\title{
Estudo sobre a Visão do Professor em Relação à Argumentação e Prova Matemática na Escola
}

\author{
Study on Teacher Views in Relation to Argumentation and Mathematical \\ Proof in School
}

\author{
Carlos Augusto Aguilar Junior ${ }^{*}$ \\ Lilian Nasser $^{* *}$
}

\begin{abstract}
Resumo
Neste artigo relatamos a segunda fase de uma pesquisa em desenvolvimento no âmbito do mestrado acadêmico do PEMat-IM/UFRJ ${ }^{* * *}$ na qual nove professores da rede pública e privada do Ensino Básico do Rio de Janeiro emitiram suas avaliações a respeito da prova matemática e analisaram respostas dadas por alunos a duas questões que versavam sobre a temática da argumentação e prova de resultados matemáticos. A metodologia de pesquisa empreendida foi de caráter qualitativo, realizada através da aplicação de formulários e sua posterior análise. Este levantamento inicial, que serviu como piloto para a pesquisa, indica a preferência dos professores por argumentos e provas que se aproximam do modelo acadêmico de prova matemática, tendo em vista o contato mais tecnicista com este tema e a pouca vivência do mesmo em sala de aula. Para tentarmos responder aos questionamentos da pesquisa, iremos aumentar a amostra de formulários e também realizar entrevistas com alguns dos participantes.
\end{abstract}

Palavras-chave: Argumentação. Prova Matemática. Ensino-aprendizagem de Prova Matemática. Saberes Docentes sobre Prova Matemática.

\begin{abstract}
In this article, we report the second phase of an ongoing research within the academic master's PEMatIM/UFRJ*. Nine teachers from public and private primary schools in Rio de Janeiro gave their assessments with respect to mathematical proof and analyzed students' responses to two questions focusing on argumentation and proof of mathematical results. The research methodology undertaken was qualitative, accomplished through the application of forms and further analysis. This initial survey, used as a pilot for the research, indicates the teachers' preference for arguments approaching the academic model of mathematical proof, considering a more
\end{abstract}

\footnotetext{
Mestre em Ensino de Matemática pelo Programa de Pós Graduação em Ensino da Matemática (PEMAT), Instituto de Matemática Universidade Federal do Rio de Janeiro (IM/UFRJ). Colégio Universitário Geraldo Reis (COLUNI/UFF), Niterói, RJ, Brasil. Endereço para correspondência: Rua Noêmia Correa, 43, casa 04, CEP: 20745-190, Rio de Janeiro, RJ, Brasil.E-mail: carlosaugustobolivar@ hotmail.com.

** Doutora em Educação Matemática pela Universidade de Londres. Instituto de Matemática Universidade Federal do Rio de Janeiro (IM/UFRJ), Rio de Janeiro, RJ, Brasil. Endereço para Correspondência: Rua Leopoldo Miguez, 99/601, CEP: 22060-020, Rio de Janeiro, RJ, Brasil.E-mail: liliannasser@uol.com.br.

**** Programa de Pós-graduação em Ensino de Matemática, do Instituto de Matemática, da Universidade Federal do Rio de Janeiro-UFRJ.
} 
technical contact with this subject and the little experience of this content in the classroom. To answer the research questions, we will increase the sample forms and conduct interviews with some of the participants.

Keywords: Argumentation. Mathematical Proof. Teaching-Learning of Mathematical Proof. Teachers' Knowledge on Mathematical Proof.

\section{Introdução}

É importante refletirmos sobre o que é saber Matemática. Há quem pense, e o senso comum corrobora para isto, que saber Matemática é ser bom nas contas e na memorização de fórmulas. Nós, professores, muitas vezes somos influenciados em nossa prática pedagógica por esta ideia recorrente, negligenciando o desenvolvimento de habilidades cognitivas importantes para o desenvolvimento intelectual do ser.

Os Parâmetros Curriculares Nacionais de Matemática - PCN (BRASIL, 1997) indicam caminhos para a formulação de um currículo de Matemática que permita desenvolver o saber matemático nos estudantes, ao postular que a Matemática:

permite resolver problemas da vida cotidiana, tem muitas aplicações no mundo do trabalho e funciona como instrumento essencial para a construção de conhecimentos em outras áreas curriculares. Do mesmo modo, interfere fortemente na formação de capacidades intelectuais, na estruturação do pensamento e na agilização do raciocínio dedutivo do aluno (p. 15).

Em nossas aulas, constata-se que o conhecimento matemático dos alunos se restringe ao domínio de técnicas operacionais, fórmulas e procedimentos, sem que haja uma compreensão do que estão fazendo. Este pensamento é revelado por Almeida (2007), no âmbito do relato de sua pesquisa de mestrado, ao discorrer sua experiência docente, tanto em nível básico quanto superior, onde percebe:

a aguda deficiência, evidenciada por parcela considerável da população estudantil, no trato de questões matemáticas mais elaboradas no que concerne à profundidade do raciocínio lógico-dedutivo exigida para o encaminhamento das questões (p. 14).

É importante voltarmos nosso olhar para um dos agentes do processo de ensinoaprendizagem: o professor de Matemática. Será que nosso professor está consciente desta necessidade? Será que nosso professor estimula no aluno a construção do raciocínio matemático?

Estes questionamentos nos levaram a refletir sobre o papel do professor na construção de um trabalho pedagógico que fomente o raciocínio matemático, a partir de uma proposta que abranja o trabalho de argumentação e justificação em Matemática. 
Acreditamos que a grande maioria dos estudantes ingressos na faculdade de Matemática escolhe este curso por curiosidade e encantamento surgidos durante os anos de ensino básico: encantamento com a própria ciência matemática e curiosidade por compreender e descobrir de onde vêm e como são estruturados os teoremas, as fórmulas, as propriedades, que são ensinados como se fossem tirados da cartola, verdades incontestáveis ou, nas palavras de Imenes (1987), dogmas.

Aqui no Brasil, antes do Movimento da Matemática Moderna no final da década de 60, o ensino, principalmente de geometria, baseava-se no modelo axiomático e dedutivo proposto em "Os Elementos", de Euclides. A partir dos anos 70, com o surgimento do Movimento da Matemática Moderna, ocorre um rompimento com o modelo de ensino axiomatizado, passando-se ao "abrandamento da exigência de se demonstrar os teoremas" (IMENES, 1987, p. 57). A partir de então, constata-se a renúncia tácita (talvez tática) de se ensinar Matemática através de modelos dedutivos, tornando assuntos que estão encadeados em sequência lógico-dedutiva em conteúdos estanques, sem ligações e implicações.

Além disso, tendo em vista que a capacidade de argumentar e provar em Matemática é importante tanto para o desenvolvimento em Matemática quanto para a formação do cidadão crítico, pode-se supor que, em geral, esta habilidade não é desenvolvida pelos professores de Matemática em suas salas de aula, seja por comodismo, desmotivação ou ausência de alternativas didáticas, como especula Almeida (2007, p. 2). O professor, para manter-se numa zona de conforto, assume o papel de transmitir conhecimentos, apresentar ou informar (IMENES, 1987. p. 57) os resultados e, ao final, aplicar e corrigir uma série de exercícios sobre o tema abordado, como revela também Almeida (2007). Aos alunos, cabe acumular as informações prestadas pelos professores e realizar as tarefas aplicadas. Este modelo de ensino-aprendizagem causa a falsa impressão de que o aluno sabe Matemática, mas este não cumpre seu papel de desenvolver no aluno o raciocínio lógico-dedutivo.

Conforme se depreende dos PCN (BRASIL, 1997, p.26), um dos objetivos do papel da Matemática no Ensino Fundamental é o desenvolvimento no educando da capacidade/habilidade de comprovação, argumentação e justificação, com vistas à formação do cidadão crítico, além de propiciar que a Matemática seja encarada pelo estudante como um conhecimento que possibilita o desenvolvimento de seu raciocínio e de sua capacidade expressiva, principalmente. Para tanto, o ensino de Matemática deve apoiar-se em estratégias que explorem o raciocínio lógico-dedutivo. 
Para o desenvolvimento deste raciocínio, é importante que o professor compreenda e aceite diversos níveis de argumentação que os alunos possam vir a apresentar para provar um dado resultado, compreender a relação dos elementos cognitivos com a faixa etária do educando e os conhecimentos adquiridos até a presente fase escolar.

Considerando a existência de níveis de argumentação, deve haver uma reconsideração dos critérios de julgamento acerca da validade formal de provas, ou seja, reavaliar o valor de uma argumentação dada a um determinado resultado. Neste sentido, Hanna (1990) cita a reavaliação realizada por matemáticos e professores de Matemática ocorrida nas décadas de 1970 e 1980 quanto ao papel das estruturas axiomáticas e das provas formais. Segundo a autora,

neste novo olhar, as provas passam a ter diferentes graus de validade formal, mantendo o mesmo grau de aceitação, permitindo com isso a reconsideração do que poderia ser prova ideal e de que se deveria ensinar nas escolas (p. 8).

Ainda de acordo com Hanna (1990), o nível de aprendizagem do aluno e o nível de exigência quanto ao valor do argumento dado para se comprovar uma declaração matemática não devem necessariamente seguir os padrões de rigidez quanto à validade de proposições, defendida na Academia. Desse modo, percebe-se que muitos educadores matemáticos assumem uma postura de afastamento quanto à exigência ou dependência extrema de provas rigorosas em Matemática, dando ênfase na concepção de prova como argumento convincente.

Esta (re)avaliação está diretamente ligada ao ensino de prova. Provar um resultado matemático é validar a declaração feita, a partir de hipóteses verificadas e certificadas como verdadeiras. Ensinar por meio de uma prova consiste em mostrar ao educando a validade da declaração feita, exibindo as etapas do processo dedutivo, para assim desenvolver no educando o raciocínio lógico-dedutivo e com isto possibilitar a construção de habilidades e competências, com aquelas registradas nos PCN's.

\section{Questões de estudo e metodologia empregada}

Enquanto professor de Matemática, preocupa-me também constatar que a grande maioria de nossos alunos não sabe justificar afirmações simples, o que pode refletir negativamente na construção de sua cidadania. A Escola não o está formando como cidadão crítico, que saiba, quando concordar ou discordar de situações, expor argumentos e justificativas que validem seu ponto de vista. Penso que a Matemática é a disciplina escolar 
que possibilita este trabalho de argumentação e prova. É objetivo deste trabalho entender como se dá a compreensão e a aceitação dos professores quanto às argumentações e provas dadas pelos alunos.

Por esta razão, esta pesquisa procura responder estas duas questões:

- $\quad$ Como o professor desenvolve em seus alunos a habilidade de argumentação e prova em Matemática?

- Como o professor avalia os tipos de argumentação apresentados pelos alunos?

O Referencial Teórico que utilizamos trata o professor e sua relação com o ensinoaprendizagem de prova matemática no Ensino Básico (Hanna (1990), Knuth (2002), Healy, Jahn e Pitta Coelho (2007), Jones (1997) e Boavida (2005)). Para estudar a prova matemática, argumentação e justificação na sala de aula sob o olhar do aluno, os tipos e esquemas de prova percebidos em respostas apresentadas por estudantes, fazemos referência aos trabalhos de Balacheff (1982, 1988), Hoyles (1997), Godino e Recio (1997), Harel e Sowder (1998).

Para tanto, constituímos inicialmente uma pesquisa com alunos do Ensino Fundamental para obter dados reais, respostas de alunos a questões que lhes exigiam estruturar argumentos e justificativas para comprovar a validade ou não da afirmação matemática Os resultados deste estudo podem ser encontrados em Aguilar Junior e Nasser (2012). Num segundo momento, que é objeto de relato deste artigo, montamos com estas respostas discentes o formulário voltado aos docentes do Ensino Básico, com inspiração no trabalho realizado por Hoyles (1997) no Reino Unido.

\section{Analisando os resultados do formulário do docente}

O formulário dos docentes se estrutura em quatro páginas. Na primeira, o docente se identifica, relata sua experiência docente nas redes pública e privada de ensino, além de cursos de qualificação profissional, e responde, de forma livre, a pergunta: Como você definiria uma 'prova matemática'?. Pietropaolo (2005) destaca a importância de ter conhecimento sobre o que é prova matemática. Para que um professor possa avaliar a argumentação e a justificação apresentadas por seus alunos e considerá-las como uma prova matemática, é necessário que este mesmo professor 
tenha estabelecido uma definição de prova matemática. Este pesquisador constatou durante entrevistas com professores um sentido para a palavra prova, que consiste em:

recurso pedagógico bastante rico nas aulas de Matemática (...), desde que se admita um sentido mais amplo para essa palavra. Não caberia a simples reprodução (...), mas sim o 'fazer matemática' em sala de aula, envolvendo assim, experimentações, $\begin{array}{llll}\text { conjecturas } \quad \text { e } & \text { argumentações. } & \text { (p. }\end{array}$

Esta definição de prova matemática, para o professor de matemática da escola básica, deve estar muito clara, e este profissional deve também perceber que a prova matemática desenvolvida com os alunos da escola básica não precisa, necessariamente, seguir os padrões de rigor exigidos pela Academia. Nas análises que os participantes dessa pesquisa realizaram sobre as respostas dos alunos, percebemos esta influência da formalidade, como veremos mais à frente.

Na segunda página do formulário de coleta de dados havia uma tabela, que deveria ser preenchida segundo uma escala. Nela, pedimos que o professor registrasse suas impressões sobre a sua própria formação, em termos de prova matemática, e sobre sua prática docente ligada ao ensino-aprendizagem da prova matemática.

Tabela 1 - Questões referentes às concepções docentes quanto à argumentação, à justificação e à prova matemática e seu ensino

\begin{tabular}{|c|c|}
\hline 2. Em Parte $\quad$ 3. Não & Respostas: \\
\hline $\begin{array}{l}\text { a) Durante minha formação, houve estímulo à prática docente voltada ao ensino- } \\
\text { aprendizagem de prova matemática. }\end{array}$ & \\
\hline $\begin{array}{l}\text { b) Na instituição em que me formei, havia alguma(s) disciplina(s) que explorava(m) o } \\
\text { ensino-aprendizagem de prova matemática na escola básica. }\end{array}$ & \\
\hline $\begin{array}{l}\text { c) Minhas aulas e planejamentos abordam a argumentação e a justificação no processo de } \\
\text { ensino-aprendizagem da Matemática. }\end{array}$ & \\
\hline $\begin{array}{l}\text { d) Meus alunos são estimulados, na sala de aula, a argumentar e a justificar em } \\
\text { Matemática. }\end{array}$ & \\
\hline $\begin{array}{l}\text { e) Meus alunos são estimulados nos instrumentos de avaliação (testes, listas e provas) a } \\
\text { argumentar e a justificar em Matemática. }\end{array}$ & \\
\hline $\begin{array}{l}\text { f) Nos estabelecimentos de ensino em que atuo, a equipe, ao formular o currículo e o } \\
\text { planejamento, contemplam o ensino-aprendizagem da prova matemática. }\end{array}$ & \\
\hline
\end{tabular}

Fonte: (Extraído de AGUILAR JUNIOR, 2012)

Já a terceira e quarta páginas traziam as resoluções apresentada por alunos a dois exercícios que exploravam questões relacionadas à prova matemática. Em cada exercício, o professor deveria responder aos seguintes questionamentos: Qual (ou quais) destas respostas você consideraria, numa avaliação, como errada? Explique.; A qual destas respostas você daria a maior nota? Por quê? e Qual destas respostas se parece mais com a que você daria? Por quê?? 
As perguntas apresentadas na tabela visavam identificar a opinião do professor quanto à sua formação acadêmica e a atenção dada pelas instituições de ensino superior ao ensino de prova matemática na escola básica. As perguntas constantes desta parte do formulário intentavam coletar informações que nos permitiram responder à questão de pesquisa: Existe no docente a preocupação em desenvolver em seus alunos a habilidade de argumentação e prova em Matemática?. Já nos questionamentos que propusemos após as respostas dadas pelos alunos aos problemas de argumentação e justificação, nosso objetivo foi coletar respostas docentes que nos permitiram, também, responder à questão da pesquisa: Como o docente valoriza os diversos níveis de justificativa apresentados pelos alunos?.

Até o momento da redação deste exame, oito professores haviam respondido e devolvido o formulário. Existe ainda a expectativa de retorno de outros 50 formulários que foram entregues a alunos do curso de Especialização em Matemática, da Universidade Federal do Rio de Janeiro, e também dos alunos do Mestrado Profissional em Ensino de Matemática ProfMat. Este formulário também será objeto de trabalho, como já falamos anteriormente, de uma oficina submetida ao $3^{\circ}$ SIPEMAT, que acontecerá em junho, em Fortaleza. Vamos, portanto, à análise destes formulários apresentados até o momento.

No formulário, solicitamos que os professores nos fornecessem sua experiência docente nos níveis Fundamental, Médio e Superior, tanto do ensino público quanto do privado. O levantamento apontou que, em média, os professores apresentam maior experiência no ensino público.

Tabela 2 - Tempo médio (em anos) de experiência profissional no ensino público e privado, nos ensinos fundamental, médio e superior.

\begin{tabular}{|l|c|c|}
\cline { 2 - 3 } \multicolumn{1}{c|}{} & $\begin{array}{c}\text { Tempo de experiência no Ensino } \\
\text { Público } \\
\text { (em média de anos) }\end{array}$ & $\begin{array}{c}\text { Tempo de experiência no Ensino } \\
\text { Privado } \\
\text { (em média de anos) }\end{array}$ \\
\hline Ensino Fundamental & $\mathbf{3 , 4}$ & $\mathbf{2 , 4}$ \\
\hline Ensino Médio & $\mathbf{5 , 0}$ & $\mathbf{1 , 6}$ \\
\hline Ensino Superior & $\mathbf{0 , 1}$ & $\mathbf{0 , 0}$ \\
\hline
\end{tabular}

(Extraído de AGUILAR JUNIOR, 2012)

É importante destacarmos o fato de que entre os oito participantes deste teste-piloto havia uma professora, já aposentada, com mais de 25 anos de experiência docente no ensino básico, que destoa dos demais professores. 
O registro do tempo de experiência do professor pode nos sugerir uma maior ou menor inclinação para o trabalho didático com a argumentação e a justificação, possibilitando, dessa forma conduzir o fazer pedagógico até a prova matemática em sala. Aliado a isto, na página 2 do formulário, colocamos uma tabela para que o professor respondesse a seis perguntas, dando graus Não, Em parte e Sim (vide tabela 2 acima). Desta maneira, fizemos uma associação entre o tempo de experiência docente com as convicções pessoais e curriculares quanto ao ensino-aprendizagem de prova matemática. Esta ideia se baseia na pesquisa realizada por Furinghetti e Paola (1997), na qual investigaram a performance de alunos italianos na prova da afirmação: $O$ produto de três números naturais é divisível por 6 No estudo, os pesquisadores conseguiram associar uma maior acurácia dos alunos com o currículo adotado pela escola e pelo preparo e experiência do professor.

Tabela 3 - Respostas dos professores a questionamentos sobre crenças, currículo e formação docente, em relação à prova matemática na escola básica.

(Extraído de AGUILAR JUNIOR, 2012)

\begin{tabular}{|c|c|c|c|}
\hline Questões: & Sim & Em parte & Não \\
\hline $\begin{array}{l}\text { a) Durante minha formação, houve estímulo à prática docente voltada } \\
\text { ao ensino-aprendizagem de prova matemática. }\end{array}$ & 0 & 4 & 4 \\
\hline $\begin{array}{l}\text { b) } \mathrm{Na} \text { instituição em que me formei, havia alguma(s) disciplina(s) que } \\
\text { explorava(m) o ensino-aprendizagem de prova matemática na escola } \\
\text { básica. }\end{array}$ & 2 & 0 & 6 \\
\hline $\begin{array}{l}\text { c) Minhas aulas e planejamentos abordam a argumentação e a } \\
\text { justificação no processo de ensino-aprendizagem da Matemática. }\end{array}$ & 1 & 6 & 1 \\
\hline $\begin{array}{l}\text { d) Meus alunos são estimulados, na sala de aula, a argumentar e a } \\
\text { justificar em Matemática. }\end{array}$ & 1 & 6 & 1 \\
\hline $\begin{array}{l}\text { e) Meus alunos são estimulados nos instrumentos de avaliação (testes, } \\
\text { listas e provas) a argumentar e a justificar em Matemática. }\end{array}$ & 2 & 5 & 1 \\
\hline $\begin{array}{l}\text { f) Nos estabelecimentos de ensino em que atuo, a equipe, ao formular } \\
\text { o currículo e o planejamento, contemplam o ensino-aprendizagem da }\end{array}$ & 0 & 4 & 4 \\
\hline
\end{tabular}

O objetivo dos itens (a) e (b) foi constatar como ocorreu, durante a formação do professor, seu contato com a prova matemática no âmbito da escola básica, lugar onde irá atuar este docente. Procuramos correlacionar, assim, a prática docente e formação acadêmica com o desenvolvimento de atividades didáticas aplicadas ao ensino-aprendizagem da argumentação, justificação e prova matemática.

Como se pode perceber da tabela acima, nenhum dos participantes respondeu sim ao item (a), e seis responderam não ao item (b). Isso nos revela, conforme sugerem Hanna (1990) e Knuth (2002), a ênfase no desenvolvimento, nos cursos de licenciatura, apenas da prova formal para validação dos teoremas ali apresentados, sem ressalvar que é importante preparar o professor para, em suas aulas na Escola Básica, apresentar argumentos e 
justificativas que não sejam formais, mais plausíveis, ou, nas palavras de Godino e Recio (1997), deduções informais.

Quanto aos itens (c) até (e), nosso objetivo foi constatar se o professor se preocupa em desenvolver com seus alunos a habilidade de argumentar e provar, para assim podermos responder nossa primeira questão de pesquisa. Constatamos a preferência por parte dos participantes em mostrar neutralidade, ao responderem em sua maioria em parte. Isso nos leva a pensar que na maioria das atividades em sala de aula o professor não abre espaço para a discussão sobre a formulação e busca de argumentos e justificações que validem uma determinada afirmação matemática, ou mesmo que formulem ou refutem conjecturas. É muito comum em nossas aulas nossos alunos tentarem formular regrinhas, ensaiando frases como “então é sempre assim...", "é sempre desse jeito...”, sem que sejam conduzidos formalmente pelo professor a estas deduções. Iremos fundamentar melhor estas conclusões a partir das entrevistas que iremos realizar com os professores selecionados.

O objetivo do item (f) era verificar como está a realidade da sala de aula da Escola Básica em relação ao ensino-aprendizagem da argumentação e justificação, voltando o olhar para o planejamento das aulas e o currículo adotado. Revela a coleta de dados que nenhum dos participantes formula, nos estabelecimentos em que atua, planejamentos ou segue currículos que contemplem o trabalho didático-pedagógico com argumentações e provas matemáticas, refletindo exatamente a falta de um olhar da Academia sobre este tema voltado para a Escola Básica, como já percebida pelas respostas obtidas no item (b).

Numa análise breve, percebemos que, em média, a maioria dos professores adotou a resposta Em parte. Esta convergência de respostas pode nos indicar que professor não realiza um trabalho constante, ordenado e planejado com argumentação e justificação em aula, passando-nos a ideia de que é esporádico e rarefeito. Também pode nos levar a imaginar que o professor mostra receio em afirmar que não prepara atividades, não segue currículos ou elabora planejamentos de aula que contemplem a argumentação, justificação com vistas à prova matemática, apesar de, na realidade, o professor saber da importância de se trabalhar com estas habilidades, como preconizam os PCN (BRASIL, 1997). Estas questões serão melhor respondidas a partir das entrevistas que iremos realizar com alguns destes docentes.

Nas suas últimas páginas, o formulário traz duas questões de argumentação e prova que foram aplicadas a estudantes de escolas de Ensino Básico, com respostas apresentadas por eles. A seguir, apresentamos estas questões: 
1) "Verifique se a afirmativa a seguir é falsa ou verdadeira, justificando sua resposta: "A soma de três números consecutivos é um múltiplo de 3 ".

Figura 1 - Questão aplicada a alunos do ensino fundamental e colocada no formulário dos professores.

(Extraído de Aguilar Júnior, 2012)

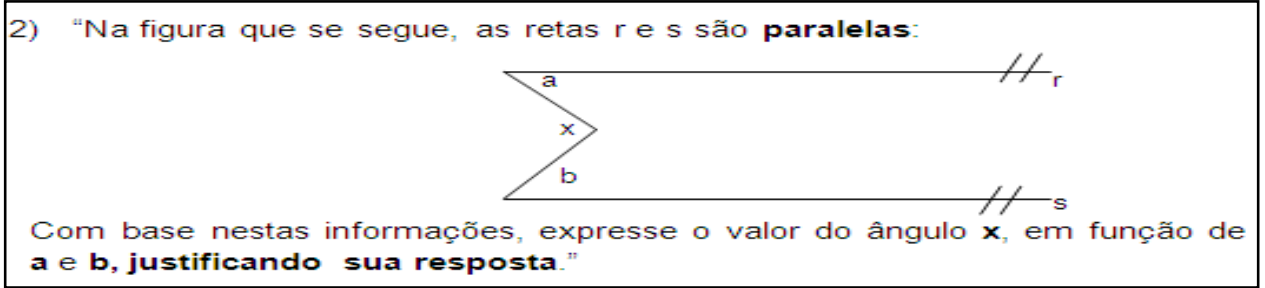

Figura 2 - Questão aplicada a alunos do ensino fundamental e colocada no formulário dos professores (Extraído de Aguilar Júnior, 2012)

Junto às perguntas, apresentamos as respostas dadas por cinco alunos do ensino básico, com nomes fictícios, a fim de preservar sua identidade. Estas respostas podem ser verificadas no Anexo 2 deste texto. O objetivo foi que o professor analisasse as respostas dos alunos às duas questões postas e respondesse aos seguintes questionamentos:

a) Qual (ou quais) destas respostas você consideraria, numa avaliação, como errada? Explique.

b) A qual destas respostas você daria a maior nota? Por quê??

c) Qual destas respostas se parece mais com a que você daria? Por quê??

Como já dito anteriormente, para que os professores possam julgar as respostas dadas pelos alunos, é importante que estes tenham alguma concepção de prova matemática. Em relação à prova matemática na Escola Básica, é importante que o professor a encare como uma argumentação muitas vezes apresentada sob a forma de experimentações, exemplos genéricos, explicações ou conjecturas, ou seja, uma prova informal, do ponto de vista acadêmico. Neste texto fizemos constar as respostas dadas pelos professores participantes à pergunta do formulário: Como você definiria uma 'prova matemática'?.

Nas oito respostas apresentadas, podemos perceber a relevância que os docentes emprestam ao rigor matemático, mostrando um olhar mais tecnicista, adquirido durante a sua formação acadêmica, quando citam que a prova matemática consta de: "sequência de implicações lógicas", "sequência de argumentos", "generalização", “conhecimentos prévios" e “definições, propriedades, teoremas e axiomas". No trabalho de Godino e Recio (1997), há uma referência à prova matemática que não segue necessariamente a ideia do rigor da prova matemática, uma vez que uma prova pode estar inserida num contexto dedutivo, que 
promove, para certo público, convencimento da validade de uma afirmação matemática. A seguir, discutiremos as respostas dadas pelos professores, e iremos nos referir a eles por nomes fictícios, de modo a preservar sua privacidade.

Sob este aspecto, percebemos que a resposta do Professor Armando se distancia da necessidade de rigor matemático defendida em outras respostas. Em sua resposta, declara:

Provar algo ao meu ver pode ser feito de qualquer forma desde que a outra parte interessada entenda. Caso contrário a prova perde o sentido. Entretanto, uma prova matemática deve seguir "passos" lógicos de tal forma que não se tenha dúvidas da certeza de tal afirmação.(AGUILAR JUNIOR, 2012)

$\mathrm{Na}$ visão deste professor, a prova possui um caráter didático, ao defender que esta pode ser construída de qualquer forma, desde que se faça inteligível ao outro - no nosso caso, o aluno - destacando ainda que, na hipótese de não se estabelecer a compreensão, a prova perde o seu sentido. Este professor foi um dos que apresentou a resposta mais voltada para sua questão didática, preocupado com seu processo de ensino-aprendizagem.

Outra resposta que mostrou sua inclinação para a realidade do aluno num ambiente de sala de aula imbuído da prova matemática foi a dada pela Professora Armênia. Em sua resposta afirma:

Uma prova em que aluno descreva o raciocínio utilizado para provar um resultado, mas que demonstre sempre que possível (ou solicitado) uma generalização do mesmo, podendo utilizar para "enriquecer" seu argumento um exemplo numérico. (AGUILAR JUNIOR, 2012)

Nesta resposta, a Professora Armênia não destaca o fato de a prova matemática apresentar uma estrutura sequencial de enunciados, que são precedidos por definições, axiomas e teoremas previamente válidos. Ela encara a prova sob o aspecto da descrição do raciocínio lógico do aluno, defendendo até mesmo o uso de exemplo numérico, remontando ao esquema empírico de prova de Harel e Sowder (1998) ou ao empirismo natural, de Balacheff (1988).

Em suma, os demais professores apresentam definições mais técnicas sobre suas concepções sobre prova matemática.

A seguir, veremos se estas concepções a respeito da prova influenciam nas avaliações realizadas por estes oito professores sobre as respostas dadas por alunos a duas questões que requeriam justificativas. Estas questões foram escolhidas porque as respostas dos alunos foram variadas, possibilitando a exploração da postura do professor frente aos diversos níveis e tipos de prova. 


\subsection{Análise das respostas dadas ao problema 1}

O problema número 1, como já citado acima, pedia que o aluno mostrasse se era verdadeiro ou falso o fato de a soma de três números consecutivos resultar num múltiplo de três. Analisaremos mais à frente as respostas que os professores participantes da pesquisa deram aos três itens $(a, b$ e c $)$.

Nossa intenção, ao desenvolver o formulário dos professores com aqueles três questionamentos, foi obter uma impressão a respeito de como o docente valoriza os diversos níveis de justificativa apresentados pelos alunos, para assim respondermos a esta questão da pesquisa.

No item a) dos problemas, o professor deveria indicar qual ou quais respostas estavam erradas, explicando esta escolha. Sete dos oito participantes indicaram como errada a resposta da aluna Renata e, dentre estes, dois indicaram também a resposta do aluno Marcelo como errada. Em relação à indicação da resposta da aluna Renata, os sete professores justificaram sua escolha por causa do argumento usado pela aluna, que considerava $x, 2 x$ e $3 x$ como três números consecutivos, o que de fato não é verdade. Quanto ao aluno Marcelo, as duas professoras que indicaram sua resposta como errada alegaram, em síntese, que o aluno não compreendera os conceitos, chegando a uma conclusão equivocada.

Chama-nos atenção o fato de os outros professores não terem avaliado como errada a resposta de Marcos. Do ponto de vista da prova, o aluno demonstrou o contrário: que não era verdade a afirmação matemática em questão, e lançou mão de argumentos equivocados, como destaca a professora Amanda: “(...) além de ter demonstrado que não entendeu os conceitos envolvidos, chegou em (sic) uma conclusão errada”.

Agora, pelo item b) os professores indicaram qual ou quais das respostas receberiam dele a maior nota, justificando esta indicação. Nesta questão, pudemos constatar vários aspectos, como questões relativas às crenças e concepções dos professores sobre avaliação e formação docente. No levantamento, constatamos que sete professores escolheram a resposta da aluna Talita, como a merecedora de maior pontuação.

Talita (16 anos): "Verdadeira. Podemos representar três números consecutivos por: $x, x+1$ e $x+2$, com $x \in \mathbb{I N}$. Somando esses números, obtemos: $x+x+1+x+2=3 x+3=3(x+1)$, que é múltiplo de $3 . "$

Figura 3 - Resposta da aluna Talita ao problema 1.

(Extraído de AGUILAR JUNIOR, 2012) 
Houve professores que indicaram esta resposta por ser da forma como ele próprio faria, como foi o caso do professor Artur. Isto pode nos apontar para o fato de o professor não ter tido contato, durante sua formação acadêmica e até mesmo em termos de experiência docente, com outros tipos de argumentações e provas. Dizemos isto por conta da resposta da aluna Marcela, que não se utilizou de "algebrismos", mas apresentou um exemplo genérico (BALACHEFF, 1988) e a partir dele empreendeu sua argumentação, ensaiando uma transição entre prova pragmática e prova conceitual, ao destacar seu raciocínio, pois a aluna observou a compensação entre os números consecutivos, rearranjando-os em trios.

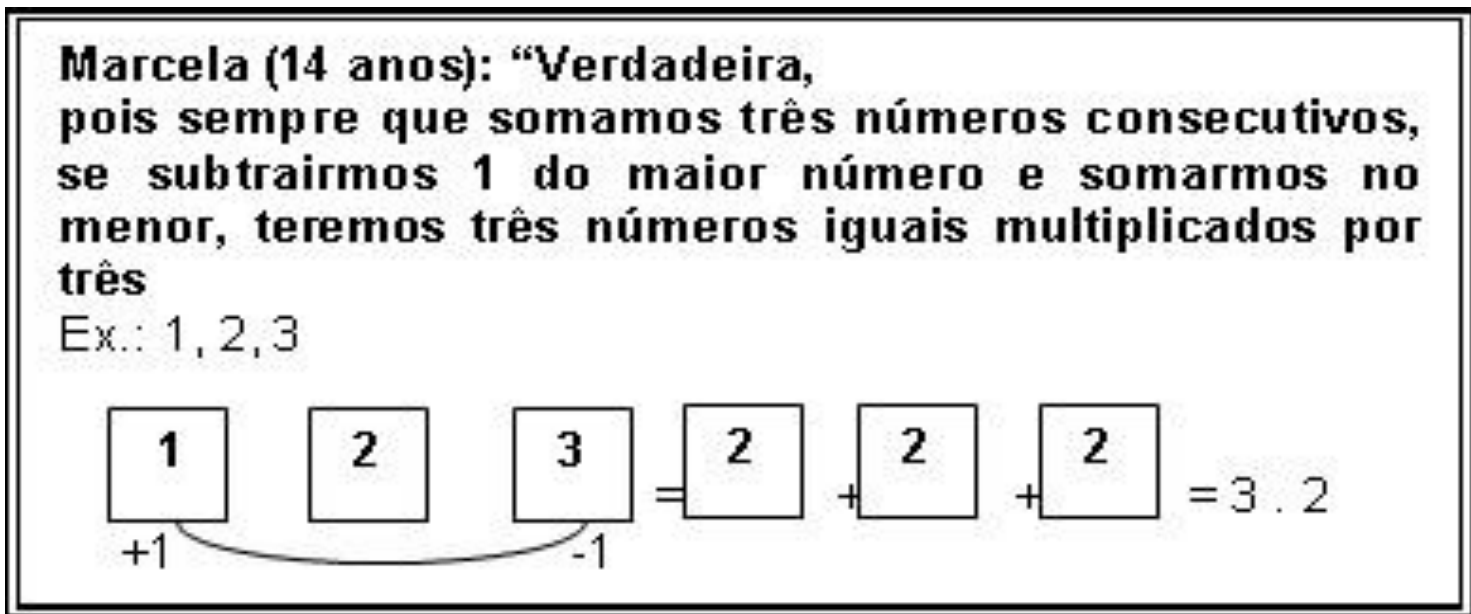

Figura 4 - Resposta da aluna Marcela ao problema 1.

(Extraído de AGUILAR JUNIOR, 2012)

Sobre a resposta da aluna Marcela, o professor Armando destaca o raciocínio apresentado pela discente e faz o seguinte comentário: "Marcela superou todos os outros ao perceber intuitivamente que o problema é reduzido a uma soma de três parcelas iguais. Uma solução extraordinária."

Percebe-se que este professor avalia a questão da prova, levando-se em conta o raciocínio dedutivo empreendido pelo aluno. Ao avaliar a resposta da Talita, ele afirma que: "Talita fez o que normalmente um professor espera de uma boa aluna."

Os demais professores valorizaram o rigor matemático presente na prova de Talita. Acreditamos que, na entrevista, se perguntarmos a respeito de qual das respostas apresentadas seria considerada por eles como uma "prova matemática", indicariam a resposta da aluna Talita. Vejamos o que os professores disseram a respeito da resposta da Talita: 
A resposta dada pela aluna Talita, que além de demonstrar entendimento a respeito dos conceitos envolvidos no problema, conseguiu chegar a uma generalização sem que fosse preciso recorrer a um exemplo específico para justificar sua conclusão. (AGUILAR JUNIOR, 2012)

Talita, pois usou rigor na sua demonstração apresentando a generalização de três números consecutivos. Não usou exemplos, que torna 'frágil' a demonstração (AGUILAR JUNIOR, 2012)

Talita. Observou que números consecutivos podem ser representados por $x, x+1 e$ $x+2$ e que a soma desses é da forma $3 k$ (AGUILAR JUNIOR, 2012)

Já o item c) requereu dos participantes a indicação de qual das respostas seria igual ou mais próxima daquela que ele daria, se o problema fosse proposto para eles. Houve professores que não apresentaram a mesma resposta para os itens b) e c). Novamente, o Professor Armando indica, no item c), que a resposta que mais parecida com a dele é a da aluna Talita, pois ele afirma que os professores foram assim formados, ou seja, a noção de prova que os professores trazem consigo é aquela trabalhada nos cursos universitários de formação de professores, que é a prova formal. De fato, alguns professores responderam ao item c) indicando a resposta de Talita devido à questão do rigor e, nas palavras da Professora Amanda, “à formalidade mais adequada à demonstração matemática".

Retornando aos professores que responderam ao item c) com algumas diferenças em relação ao que responderam no item b), destacamos as respostas apresentadas pelos professores Armênia e Aurélio:

De acordo com o trabalho desenvolvido como professora, perpasso pelas respostas do aluno Estevan e pela resposta da aluna Talita, iniciando com o desenvolvimento através de exemplos para mostrar uma possível regularidade e depois formalizo. Como resposta final, minha resposta se parece mais com a da aluna Talita. (AGUILAR JUNIOR, 2012)

Depende da necessidade. Para meus alunos ou, por exemplo, em uma prova de um concurso? Para meus alunos usaria primeiro a forma de Marcela e depois a de Talita. A de Marcela é mais simples. Ao meu ver, é mais forte que a outra para justificar para os alunos, embora a segundo seja a formal. (AGUILAR JUNIOR, 2012)

Nestas respostas, os professores revelam suas concepções didático-pedagógicas com respeito à argumentação e à prova matemática, destacando a importância de se iniciar um processo de desenvolvimento destas habilidades passando de estruturas mais simples, apoiadas em exemplos numéricos para depois avançar ao estágio da prova formal, com uso de estruturas mais gerais. 
Julgamos interessante a resposta do Professor Aurélio quando indaga a respeito da necessidade de se apresentar uma prova. Em sua resposta, identificamos a preocupação do professor com respeito aos interlocutores, a quem esta prova estará endereçada, a quem se deseja convencer, reforçando à ideia de Godino e Recio (1998), na qual o termo prova pode apresentar múltiplos significados, dependendo do contexto social e institucional em que está inserido.

Em última análise, percebemos uma preferência por respostas que remetem ao rigor e ao formalismo, como foi o caso da resposta da aluna Talita. Mesmo se tratando de alunos de Ensino Fundamental, os professores, em sua maioria, não valorizaram a questão do raciocínio lógico-dedutivo demonstrado em algumas respostas, como a da aluna Marcela. Em sua resposta, constatamos, como já mencionado, o processo de transição da prova pragmática para a prova conceitual (BALACHEFF, 1988), refletindo um empreendimento intelectual pouco usual nas salas de aula e que não foi valorizado por seis participantes. Outro fato que destacamos é o de não terem mencionado a resposta do aluno Estevan:

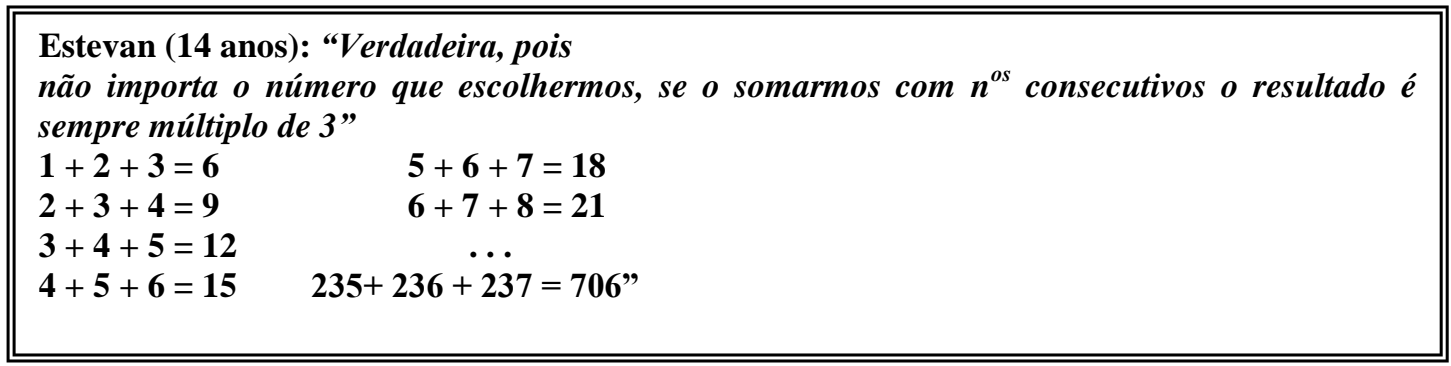

Figura 5 - Resposta do aluno Estevan ao problema 1 (AGUILAR JUNIOR, 2012)

A resposta de Estevan se enquadra no esquema de prova empírico, baseado em exemplos (HAREL e SOWDER, 1998), ou ainda no tipo de prova pragmática do empirismo natural (BALACHEFF, 1988). Em nível de Escola Básica, especificamente no Ensino Fundamental, onde os alunos estão iniciando o processo de transição do concreto para o abstrato, é importante que o professor valorize este raciocínio. Apesar de a academia não considerar válida uma prova ou demonstração baseada em exemplos, o professor da Escola Básica deve encorajar este empreendimento inicialmente, uma vez que a conquista da habilidade da prova matemática depende da passagem de provas informais a formais, da prova pragmática à prova conceitual, nas palavras de Balacheff (1988). Sobre esta resposta, os professores Armênia e Armando fazem as seguintes colocações:

A resposta do aluno Estevan, embora esteja composta apenas de exemplos, não caracterizando sua generalização, não está errada. (AGUILAR JUNIOR, 2012) 
Estevan observou casos particulares e não generalizou, cabe uma discussão em sala usando este exemplo (AGUILAR JUNIOR, 2012)

\subsection{Análise das respostas dadas ao problema 2}

O problema 2 referiu-se a uma questão de geometria, referente ao teorema das paralelas. No problema, o aluno deveria concluir que o ângulo x media $a+b$, apresentando argumentos que validassem este resultado. A estrutura das perguntas no problema 2 foi idêntica àquela apresentada no problema 1. Vamos, então, à análise das respostas dos participantes a estes itens.

Comparando este problema ao primeiro, constatamos que as respostas dos professores foram mais diretas, com relação a emitir um julgamento da questão. Devemos este fato à estrutura lógica da Geometria Euclidiana, baseada na dedução, a partir de conceitos primitivos, axiomas e teoremas e proposições previamente provados. Percebemos que as respostas discentes que utilizaram argumentos equivocados ou conceitos distorcidos foram diretamente classificadas como erradas. Neste sentido, as respostas que mais receberam indicação de errada foram aquelas dadas pelos alunos Renata, Pietra e João. Estas respostas podem ser consultadas no Anexo 2, deste texto. No item b), perguntamos qual ou quais respostas deveriam receber maior pontuação. No levantamento que realizamos, houve unanimidade na indicação da resposta do aluno Matheus como a que mereceria maior nota.

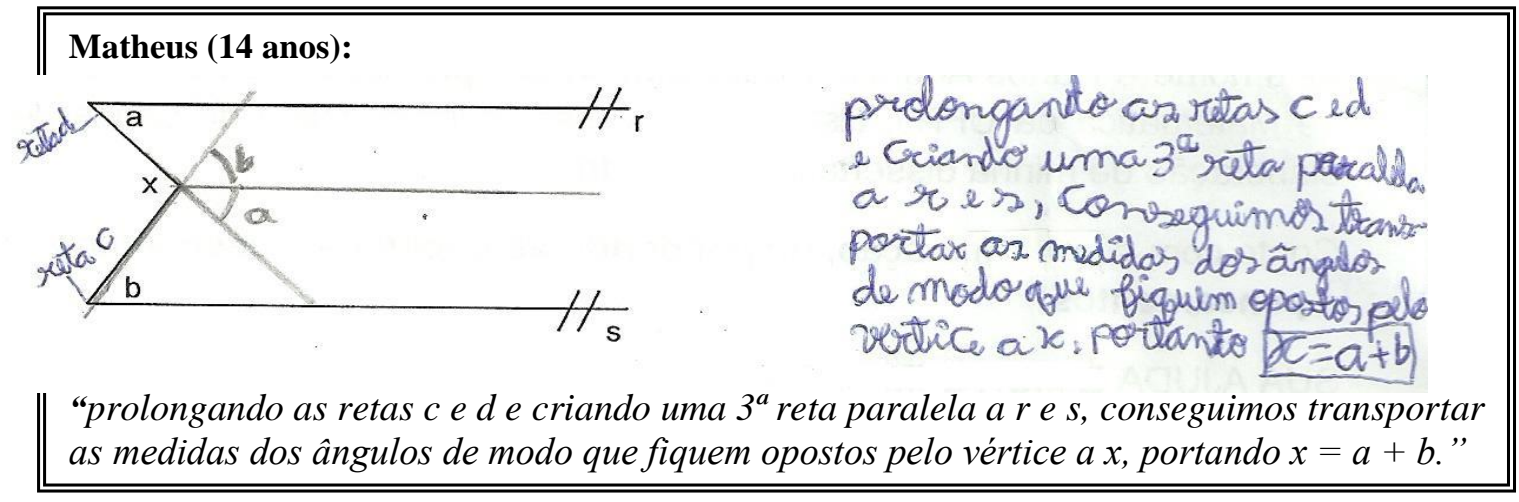

Figura 6 - Resposta do aluno Matheus ao problema 2

(Extraído de AGUILAR JUNIOR, 2012)

Nesta resposta, o aluno utilizou construções auxiliares e os resultados previamente conhecidos (axioma das paralelas, teorema das paralelas e ângulos opostos pelo vértice) para mostrar que $x=a+b$. A redação de sua argumentação indica um raciocínio mais formal, já assentado no tipo de prova conceitual de Balacheff (1988) ou ainda no esquema de prova analítico, do tipo axiomático (HAREL e SOWDER, 1998). Este exemplo sugere um esquema 
próximo aquele aceito pela comunidade matemática, o que Balacheff (1982) chamaria de demonstração. Mais uma vez percebemos a influência da Academia sobre as concepções dos professores com respeito à prova matemática, até mesmo sobre os mais experientes, como a Professora Amélia, que apresenta 25 anos de experiência docente. Ela respondeu o item b) da seguinte maneira:

Matheus. Sua linguagem é clara, argumentou mediante definições ensinadas anteriormente apesar que (sic) 'transportar' substitui, na sua demonstração, o conceito de ângulos correspondentes. (AGUILAR JUNIOR, 2012)

Vimos nesta resposta a influência da Academia, como afirmamos anteriormente. É nos cursos universitários de formação docente que deparamos com a prova matemática e demonstração como define Balacheff (1982). De fato, nos livros didáticos atualmente empregados não iremos encontrar uma argumentação deste, ou de outros resultados, que possa ser considerada uma prova válida. Porém, devemos nos atentar que o desenvolvimento da habilidade de prova e demonstração deve passar por uma evolução, cujo estágio inicial é a apresentação de argumentos convincentes e consistentes.

Das respostas discentes colocadas no formulário, havia outra que poderia ser considerada como correta, ou merecer uma nota maior que as de João, Pietra e Renata:

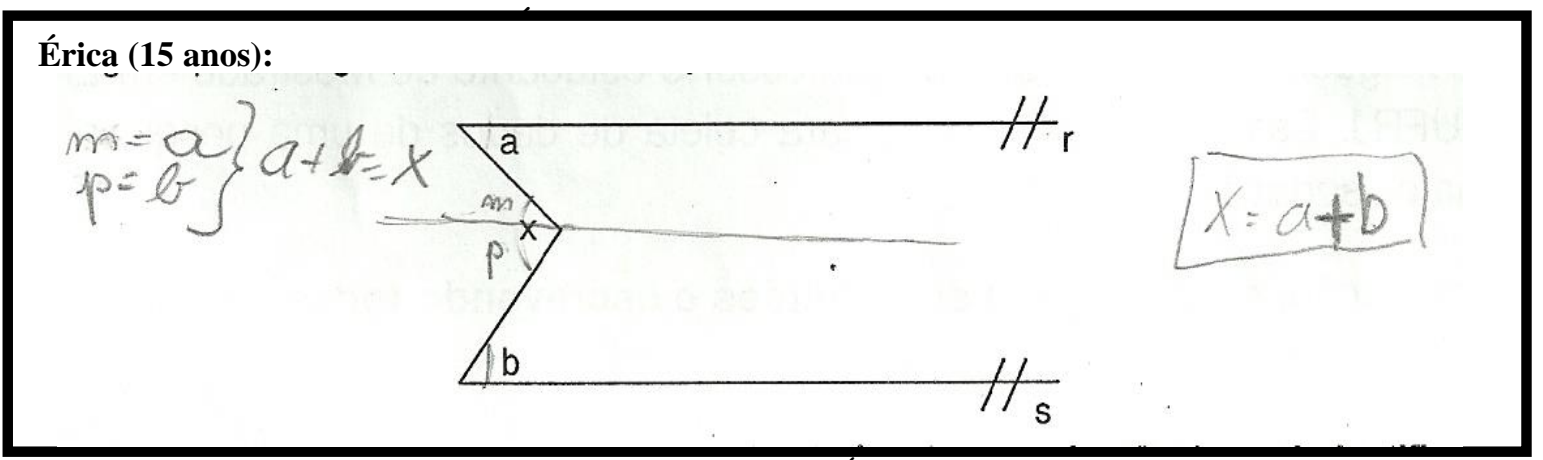

Figura 7 - Resposta da aluna Érica ao problema 2 (AGUILAR JUNIOR, 2012)

Esta resposta nos mostra a utilização de informações mais gráficas do que escritas. No trabalho realizado por Hoyles (1997), há o relato de argumentos gráficos para justificar que a soma de dois números ímpares resultava em um número par. Em nossa análise, consideramos que esta resposta também pode ser considerada gráfica, por que a aluna utilizou-se basicamente da construção da reta paralela auxiliar para poder aplicar o teorema das paralelas. A este respeito, a Professora Amanda responde assim ao item c), em que perguntamos, como no problema 1, que resposta se pareceria mais com a do próprio professor: 
Caso não tivesse que demonstrar, eu responderia como a Érika, pois foi sucinta e autoexplicativa. (AGUILAR JUNIOR, 2012)

Outros professores também indicam no item c) a resposta da aluna Érica, ressaltando a objetividade e a autoexplicação, como declarado pela Professora Amanda e ainda pelo fato de terem aprendido da mesma forma, como afirmam os professores Armando e Artur. Acreditamos que, ao afirmarem que responderiam como Érica por terem aprendido da mesma forma, os professores estavam referindo-se a sua vida escolar, pois a prova, no contexto institucional universitário, demandaria o emprego de deduções a partir de outros resultados e definições, como o fez Matheus. Mais uma vez se constata, como já percebido anteriormente, que alguns cursos universitários de formação de professores não se preocupam em oferecer disciplinas que explorem a questão da argumentação e prova matemática na Escola Básica, ou então em promover debates sobre as provas matemáticas apresentadas, de modo a subsidiar para os professores uma transposição didática deste entendimento ou desta habilidade para a Escola Básica.

\section{Algumas considerações}

Como dito anteriormente, este trabalho ainda se desenvolverá numa terceira e última fase, que é a da entrevista com alguns dos professores que responderem ao formulário. $\mathrm{Na}$ entrevista, entendemos que o professor expressará de viva voz suas impressões. Queremos com isto, através do estudo de casos, subsidiar algumas conclusões que obtivemos ao analisar as respostas dos professores, como, por exemplo, conhecer suas concepções de prova matemática, verificar como realmente lidam com a questão do ensino-aprendizagem desta habilidade em sala de aula e quais foram os critérios utilizados para julgar as respostas dos alunos. Esperamos que nos próximos meses, em junho e julho, possamos entrevistar ao menos quatro participantes, para assim tentar responder às questões de pesquisa colocadas e assim contribuir para esta área de pesquisa em Educação Matemática.

\section{Referências}

AGUiLAR JUNIOR, C. A. Postura de Docentes quanto aos tipos de Argumentação e Prova Matemática apresentados por alunos do Ensino Fundamental. 2012. 144f. Dissertação (Mestrado 
em Ensino de Matemática) - Programa de Pós-graduação em Ensino de Matemática - Instituto de Matemática, Universidade Federal do Rio de Janeiro, Rio de Janeiro, Brasil, 2012.

AGUILAR JUNIOR, C. A; NASSER, L. Analisando justificativas e argumentação matemática de alunos do ensino fundamental. Revista Vydia - UNIFRA, Santa Maria/ RS, Brasil/ v. 32, n. 2, p. 133147, set. 2002.

ALMEIDA, J. C. P. Argumentação e prova na matemática escolar do ensino básico: A soma das medidas dos ângulos internos de um triângulo. 2007. 221 f. Dissertação (Mestrado Profissional em Ensino de Matemática) - Programa de Pós-graduação em Educação Matemática, Pontifícia Universidade Católica - SP, São Paulo, Brasil. 2007.

BALACHEFF, N. Preuve et démonstration mathématique au collège. Recherches en didactique des mathématiques. La Pensée Sauvage Éditions, Grenoble, França. v.3, n.3, p. 261-304, 1982.

BALACHEFF, N. Aspects of proof in pupils' pratice of school mathematics. In: PIMM, D. (Ed.). Mathematics, teachers and children, Hodder \& Stoughton: Londres, Inglaterra, p. 216-235, 1988.

BOAVIDA, A. M. R. A argumentação na aula de Matemática: Olhares sobre o trabalho do professor. In: AMRB: XVI SIEM, 16. 2005, Lisboa, Portugal, Proceendings... Lisboa, Portugal: AMRB. 2005.

BRASIL. Parâmetros Curriculares Nacionais: Matemática. 88f. Secretaria de Ensino Fundamental - SEF/MEC - Brasília, Brasil. 1997.

FURINGHETTI, F. e PAOLA, D. Shadows on Proof. PME 21, Lahit, Finlândia, v. 2, n. 1, p. 273-280, Jun. 1997

GODINO, J. D.; RECIO, A. M. Meaning of Proofs in Mathematics Education. PME 21, Lahit, Finlândia, n. 1, v. 2, p. 313-320, Lahit, Finlândia. Jun. 1997.

HANNA, G. Some Pedagogical Aspects of Proof. Interchange. The Ontario Institute for Studies in Education, Ontario, Canadá. v. 21, n.1, p. 6-13, Mar. 1990.

HAREL, G.; SOWDER, L. Types of Student's Justifications. The Mathematics Teacher. NCTM, Estados Unidos. v. 91, n. 8, p. 670-675, Nov. 1998.

HEALY, L.; JAHN, A. P.; PITTA COELHO, S. Concepções de Professores de Matemática sobre prova e seu ensino: mudanças e contribuições associadas à participação em um projeto de pesquisa. In: Anais da $30^{\text {a }}$ Reunião Anual da ANPEd: 30 anos de pesquisa e compromisso social, 30, 2007, Caxambu, Brasil.

HOYLES, C. The Curricular Shaping of Students' Approaches to Proof. For the Learning of Mathematics, 17, n. 1, p. 7-15, Fev. 1997.

IMENES, L. M. A. Geometria no primeiro grau: experimental ou dedutiva? Revista de Ensino de Ciências (USP), São Paulo, v. 1, n. 19, p. 55-61, out. 1987. Brasil.

JONES, K.; Student-Teachers' Conceptions of Mathematical Proof. Mathematics Education Review, Londres, Inglaterra, v. 9, n. 9, p. 16-24, Abr. 1997.

KNUTH, E. J. Teacher's conceptions of Proof in the context of secondary school mathematics. Journal of Mathematics Teacher Education, Holanda, v. 1, n. 5, p. 61-88, Mar. 2002. 
PIETROPAOLO, R. C. (Re)significar a demonstração nos currículos da Educação Básica e da Formação de Professores de Matemática. 2005, 388 f. Tese (Doutorado em Educação Matemática) . Programa de Pós-graduação em Educação Matemática, Pontifícia Universidade Católica de São Paulo, São Paulo, 2005.

Submetido em Junho de 2013. Aprovado em Março de 2014. 